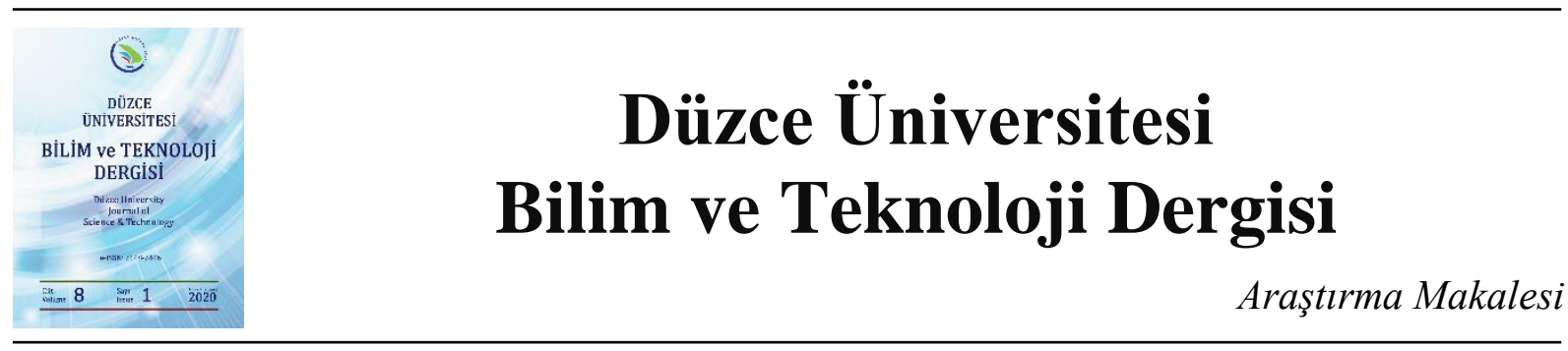

\section{Koruma Elektrotlarının Darbe Geriliminde Etkinliğinin Deneysel Olarak İncelenmesi}

\author{
(iD) Hasbi İSMAİLOĞLU a,* \\ a, ${ }^{*}$ Elektrik Mühendisliği Bölümü, Mühendislik Fakültesi, Kocaeli Üniversitesi, Kocaeli, TÜRKIYE \\ * Sorumlu yazarın e-posta adresi: hasbi@kocaeli.edu.tr
}

DOI : 10.29130/dubited.563178

\begin{abstract}
ÖZET
Güç sistemleri ve bu sistemlerde yer alan aygıtlar, çeşitli etkenlerle ortaya çıkan aşırı gerilimlerle zorlanırlar. Söz konusu zorlanmalar, sistem ve aygitlarda delinme/atlamalar oluşturarak kısa devrelere, hasarlara ve enerji kesintilerine yol açabilirler. $\mathrm{Bu}$ nedenle sistem ve aygıtlarda aşırı gerilimlere karşı koruma önlemleri alınmaktadır. Özellikle orta gerilim sistemlerinde, koruma elektrotları yoğun olarak kullanılmaktadır. Ancak, gözlem ve tecrübeler, koruma elektrotlarının beklenen fonksiyonları sağlayamadıklarını göstermektedir. $\mathrm{Bu}$ çalışmada, sistemlerde oluşan ve yürüyen dalga biçiminde yayılan aşırı gerilimlerin bazı karakteristik özellikleri tanımlanmış; bu özellikler dikkate alınarak, koruma elektrotlarının darbe gerilimi davranışları deneysel olarak incelenmiş̧ir. Elde edilen sonuçlar, koruma elektrotlarının çalışma gerilimleri ve çalışma süreleri bakımından, orta gerilim düzeylerinde, beklenen fonksiyonları sağlayamadıklarını göstermiş̧ir.
\end{abstract}

Anahtar Kelimeler: Koruma elektrotlarl, Ark boynuzları, Yürüyen dalgalar, Yıldırım darbe gerilimi

\section{Experimental Investigation of the Efficiency of Protection Electrodes under Impulse Voltages}

\begin{abstract}
The power systems and the devices in these systems are forced by the overvoltages caused by various factors. These stresses can result in short circuits, damages and power outages by creating breakdowns/flashovers in systems and devices. Therefore, some protection measures against overvoltages should be carried out on systems and devices. For this purpose, especially in medium voltage systems, protection electrodes are used extensively. However, observations and experiences have shown that the protection electrodes could not provide the expected functions. This study presents some characteristics of the systems, and of the overvoltages spreading as traveling waves on the systems. In this regard, impulse voltage response of the protection electrodes was investigated experimentally. The results showed that the protection electrodes could not provide the expected functions in terms of operating voltages and operating times at medium voltage levels.
\end{abstract}

Keywords: Protection Electrodes, Arcing Horns, Traveling Waves, Lightning Impulse Voltage

Geliş: 10/05/2019, Düzeltme: 23/09/2019, Kabul: 30/10/2019 


\section{GiRis}

Enerji sürekliliğini bozan etkenlerin başında, sistemlerde yer alan aygitlarda ortaya çıkan yalıtım bozulmaları ve bunlara bağlı olarak oluşan kısa-devreler gelmektedir. Aygıt yalıtımlarını zorlayan ve söz konusu arızalara yol açan olaylar arasında, aşırı gerilimler önemli bir yer tutmaktadır. Bu nedenle enerji kesintilerini azaltmak üzere, aşırı gerilimlerin oluşumlarına engel olunmaya çalışılmakta ve ortaya çıkan aşırı gerilimlerin etkilerini azaltmaya yönelik önlemler alınmaktadır.

Dış aşırı gerilimlerin, iletim hatları ve şalt tesislerini etkileme olasılıklarını azaltmak amaciyla çevrenin doğal koruyucu yapısından yararlanılır. Örneğin hatlar, olabildiğince yamaç, vadi gibi bölgelerden geçirilmeye çalışılır. Doğrudan yıldırım düşmelerine karşı önlem olarak koruma iletkenleri de kullanılır. Koruma iletkenlerinin görevlerini etkin biçimde yapmaları için, topraklama dirençlerinin küçük olması önem taşır. Topraklama dirençlerinin düşük tutulması ile geri atlama olasılıkları önemli oranda küçültülür [1,2].

Parafudrlar, sistemlerde yer alan aygıtları aşırı gerilimlere karşı korumak üzere, yaygın olarak kullanılan koruma elemanlarıdır. Parafudrların, dağıtım sistemlerinde genel olarak dış aşırı gerilimlere karşı; iletim sistemlerinde ise hem iç hem de dış aşrı gerilimlere karşı koruma yapmaları beklenir [3]. Çalışma karakteristikleri ve yapısal özelliklerine göre, parafudrlar başlıca iki gruba ayrılabilir. Bu gruplardan birini, günümüzde artık kullanılmayan; porselen korungaç (mahfaza) içine yerleştirilen, atlama aralıklı (eklatörlü) değişken dirençli $(\mathrm{SiC})$ parafudrlar oluşturmaktadır. Atlama aralıklarının kirlenmeye karşı çok duyarlı olması ve gecikmeli çalışma risklerinin bulunması nedeniyle artık bu tip parafudrlar üretilmemektedir [4-6]. İkinci grubu, günümüzde iletim ve dağıtım sistemlerinde yaygın olarak kullanılan metaloksit parafudrlar oluşturmaktadır. Metaloksit parafudrlar, yapılarında atlama aralıkları bulunmadığından, kirlenmeye karşı daha az duyarlıdırlar. Bu parafudrların, şebeke geriliminin etkisi altında olmaları nedeniyle normal işletme koşullarında, dirençleri üzerinden sürekli olarak küçük bir akım $(<1 \mathrm{~mA})$ geçişi olur. Bu yapı sayesinde, aşı1rı gerilimlere karşı korumada gecikmeli çalışma riskleri de düşük olmaktadır [7-10].

Diğer taraftan, iletim hatlarında izolatörlerin aşırı gerilimler sonucu hasar görmelerini önlemeye yönelik olarak, koruma elektrotları (ark boynuzları) yaygın olarak kullanılmaktadır. Basit bir yapıya sahip olan bu elektrotlar, izolatörlerde oluşabilecek yüzeysel atlama ve arkları, izolatör yüzeylerinden uzaklaştırarak, izolatörlerin zarar görmelerine engel olmak ve kısmen de olsa gerilim dağılımlarını düzenlemek amacıyla kullanılırlar.

Ancak, koruma elektrotları, çoğu zaman dağıtım transformatörlerinin geçit (buşing) izolatörlerinde de kullanılmakta ve bunların, transformatör korumasını da sağlayabilecekleri düşünülmektedir [11-13]. Koruma elektrotlarının bu amaçla kullanılabileceğine ilişkin değerlendirmeler yönetmeliklerimizde de yer almaktadır [2]. Güncel standartlarda, koruma elektrotlarının bu amaçla kullanılması önerilmemekle birlikte; ülkemizde nispeten küçük güçlü ( $\leq 400 \mathrm{kVA})$ transformatörlerde yaygın olarak kullanıldıkları görülmektedir. Bu kanının oluşmasına yol açan en önemli etken, 1960'lı yıllarda yayınlanmış olan VDE standartlarıdır $[14,15]$.

$\mathrm{Bu}$ çalışmada, enerji sistemlerinde çeşitli nedenlerle ortaya çıkan ve aygıt yalıtımlarının zorlanmasına yol açan yürüyen dalgaların bazı karakteristik özellikleri tanımlanmış ve hatlarda yayılma hızlarına ilişkin eşitlikler verilmiştir. Yürüyen dalgaların yayılma hızları dikkate alınarak, dağıtım transformatörlerinin geçit izolatörlerinde kullanılan koruma elektrotlarının, standart yıldırım darbe gerilimlerinde koruma düzeyleri deneysel olarak incelenmiştir. Elde edilen deneysel sonuçlar 1şığında, koruma elektrotlarının, aşırı gerilimlere karşı koruma etkinliği irdelenmiştir. 


\section{YÜRÜYEN DALGALAR}

Güç sisteminin herhangi bir noktasında, atmosferik olaylar, açma-kapama, daha yüksek işletme gerilimine sahip sistem iletkenlerinin teması vb. nedenlerle ortaya çıkan aşırı gerilimler, tüm sistem üzerinde etkili olurlar. Söz konusu etkiler, sistemde yürüyen dalga biçiminde yayılırlar. Bir iletim hattında, yıldırım düşmesi sonucu yürüyen dalgaların oluşumu, Şekil 1'de sembolik olarak gösterilmiştir. Buna göre, yıldırım düşmesi ile hat üzerinde, aktarılan yüke bağlı olarak $\mathrm{i}(\mathrm{t})$ akımı oluşur ve akım her iki yöne doğru $1 / 2 i(t)$ biçiminde yayılır $[1,6]$.

Üç fazlı paralel üç iletkenden oluşan bir hat için birim uzunluk başına endüktans ve kapasite değerleri; r- iletken yarıçapı, $r^{\prime}=r \cdot e^{-1 / 4}$ biçiminde tanımlı geometrik ortalama iletken yarıçapı, $D_{i j}$ - iletkenler arası uzaklıklar ve $D_{M}=\left(D_{12} \cdot D_{13} \cdot D_{23}\right)^{1 / 3}$ şeklinde tanımlanan iletkenler arası geometrik ortalama uzaklık olmak üzere, sirasıyla

$\mathrm{L}=2 \cdot 10^{-7} \cdot \ln \left(\mathrm{D}_{\mathrm{M}} / \mathrm{r}^{\prime}\right)(\mathrm{H} / \mathrm{m} \cdot \mathrm{faz})$

ve

$C=\frac{2 \pi \varepsilon}{\ln \left(D_{M} / \mathrm{r}\right)}(\mathrm{F} / \mathrm{m} . \mathrm{faz})$

eşitlikleri ile verilebilir [16,17]. Bu eşitlikler kullanılarak, yürüyen dalganın hat üzerinde yayılma hızı için,

$v \cong 1 / \sqrt{\mathrm{LC}})$

ve hattın karakteristik empedansı için de

$\mathrm{Z} \cong \sqrt{\mathrm{L} / \mathrm{C}})$

eşitlikleri elde edilebilir.

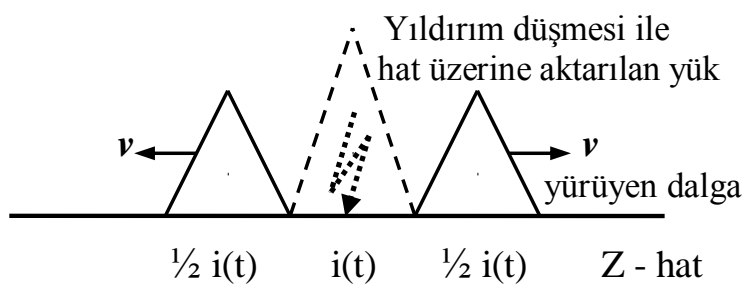

Şekil 1. Karakteristik empedansı Z olan iletim hattına yıldırım düşmesi sonucunda hat üzerinde iki yöne doğru yürüyen dalgaların oluşumu

Eşt. 1 ve 2'de verilen endüktans ve kapasite ifadeleri kullanılarak, yürüyen dalganın hava hattında yayılma hızı,

$v \cong 300(\mathrm{~m} / \mu \mathrm{s})$ 
olarak elde edilebilir. Karakteristik empedansının değeri ise hat parametrelerine bağlı olarak,

$\mathrm{Z} \cong 250-750 \Omega$

şeklinde bulunabilir. Görüldüğü gibi, yürüyen dalgalar hava hatları üzerinde yaklaşık olarak 1şık hızıyla ilerlemektedirler. Kablo gibi, katı yalıtkan içeren ortamlarda yürüyen dalgaların yayılma hızları ise boşluktaki sşık hızının yaklaşık üçte ikisi kadar olmaktadır $[1,16,19]$.

Yürüyen dalgalar, ortaya çıkmalarına yol açan olaylara ve şebekenin yapısına bağlı olarak, genlikleri, işletme geriliminin birkaç katına kadar ulaşabilen aşırı gerilimlerin oluşmasına yol açarlar. Karakteristik empedansı $Z$ olan hat üzerinde bir yönde ilerleyen ve akımı, $1 / 2 i(t)$ biçiminde ifade edilen bir yürüyen dalganın gerilimi için,

$\mathrm{U}(t)=\frac{1}{2} \mathrm{Z} \cdot \mathrm{i}(t)$

eşitliği yazılabilir. Akımın maksimum değerinin $I_{m}$ olduğu dikkate alınırsa, yürüyen dalga geriliminin maksimum değeri de,

$\mathrm{U}_{\mathrm{m}}=\frac{1}{2} \mathrm{Z} \cdot \mathrm{I}_{\mathrm{m}}$

biçiminde verilebilir [18]. Ortaya çıkan bu gerilimler, sistemde yer alan tüm aygıtların yalıtımlarının zorlanmasına neden olurlar. Yürüyen dalgalar sistemde yayılırken, örneğin hat dirençleri, kaçak iletkenlikler ve oluşan korona kayıpları nedeniyle zayıflamaya maruz kalırlar. Ancak, sistemin süreksizlik noktalarında oluşan yansıma ve kırılmalar sonucu, süreksizliğin türüne bağlı olarak gerilimlerinin genlikleri artabilir ya da azalabilir [3].

Yürüyen dalgalar, büyük güçlere sahip olmakla birlikte; genel olarak çok kısa süreli olduklarından, düşük enerjilere sahiptirler. Ancak, üzerinde yol aldıkları iletim ortamlarının karakteristik empedanslarına bağlı olarak oluşturdukları aşırı gerilimler, aygıtların yalıtımlarını bozabilmektedirler. Genel olarak, sistem üzerinde işletme gerilimi de bulunduğundan, aşırı gerilimler nedeniyle ortaya çıkan yalıtım bozulmaları şebeke kısadevrelerine dönüşebilmektedir. Şebeke kısadevreleri ise enerji kesintilerine, sistemde önemli hasarlara ve aygitların kullanılamaz hale gelmesine yol açabilmektedirler. Bu nedenlerle aşırı gerilimlerin oluşumları engellenmeye çalışılmakta, oluşmaları durumunda da olumsuz etkilerini azaltmaya yönelik önlemler alınmaktadır.

\section{KORUMA ELEKTROTLARI}

Koruma elektrotları (ark boynuzları-eklatörler), genel olarak karşılıklı iki metal çubuktan oluşan elektrotlardır. Basit yapıda olmaları nedeniyle zincir izolatörleri, transformatör geçit izolatörleri gibi aygıtlara kolaylıkla yerleştirilebilirler. Örnek olarak, bir dağıtım transformatörü üzerine yerleştirilmiş koruma elektrotları, Şekil 2'de gösterilmiştir.

Koruma elektrotlarının, izolatör bir aşırı gerilimle zorlandığında, oluşabilecek yüzeysel atlamayı ve buna bağlı olarak ortaya çıkabilecek ark1, izolatör yüzeyinden uzaklaştırmaları beklenir. Bunun yanında; koruma elektrotları, özel şekillerde düzenlenmeleri halinde, zincir tipi izolatörlerde korona halkası ve gerilim dağılımı düzenleyici donanımların işlevlerini kısıtlamazlar [20]. Aşııı gerilim etkisi ile elektrotlar arasında atlama gerçekleştiğinde, sistemde şebeke gerilimi de bulunduğundan oluşan ark, faz-toprak kısadevresine yol açar. Oluşan arkın sönmesi, yıldız noktası yalıtılmamış sistemlerde, enerjinin kesilmesine bağlıdır. 


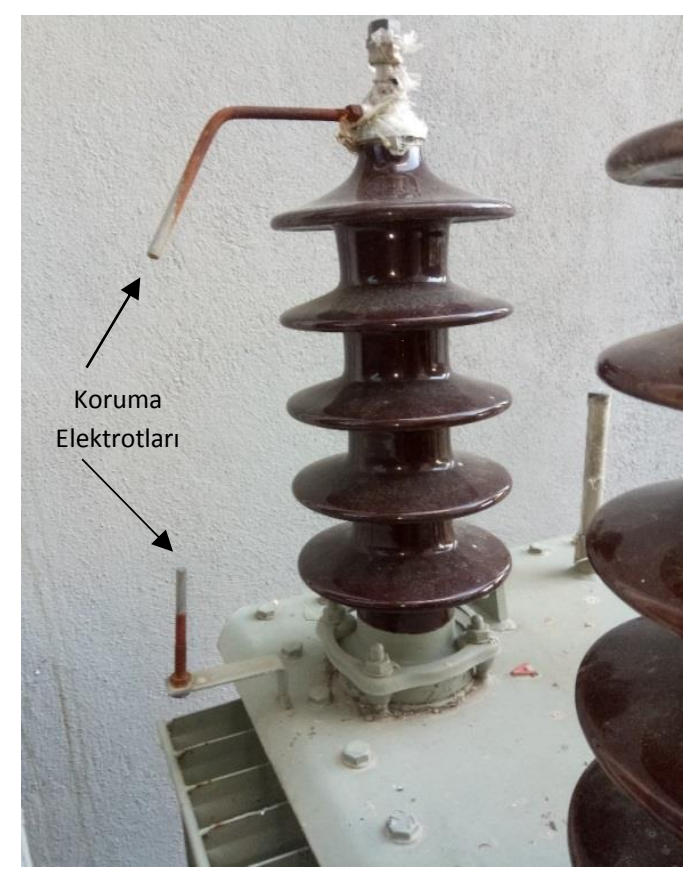

Şekil 2. Bir dă̆ıtım transformatörü üzerinde koruma elektrotlarl (ark boynuzları)

İşletme gerilimi düzeylerine göre kullanılması önerilen koruma elektrot açıklıkları Tablo 1'de verilmiştir. Tablo 1'de, aşırı gerilimlere karşı koruma elemanları kullanılması durumunda, izin verilen en yüksek aşırı gerilim değerleri de verilmiştir $[14,15]$.

Tablo 1. En yüksek işletme gerilimlerine göre koruma elektrodu açıklıkları (1000 m'ye kadar yükseklikler için)

\begin{tabular}{ccc}
\hline $\begin{array}{c}\mathbf{U}_{\mathbf{i}} \\
(k V)\end{array}$ & $\mathbf{a}$ & $\mathbf{U}_{\mathbf{k}}$ \\
\hline 7,2 & 60 & $(k V)$ \\
\hline 12 & 85 & 26 \\
\hline 17,5 & 115 & 40 \\
\hline 24 & 155 & 80 \\
\hline 27,5 & 180 & 100 \\
\hline 36 & 220 & 120 \\
\hline 72,5 & 400 & 235 \\
\hline 170 & 1000 & 565 \\
\hline 420 & 2300 & 1110 \\
\hline
\end{tabular}

Koruma elektrotları, izolatör yüzeylerinde oluşabilecek arkları izolatörlerden uzaklaştırarak, zarar görmelerine engel olabildikleri için, özellikle orta gerilim dağıtım transformatörlerinde ve yüksek gerilim iletim hatlarında yaygın olarak kullanıldıkları görülmektedir.

Bunun yanında, ülkemizde, özellikle orta gerilim dağıtım transformatörlerinde geçit izolatörlerine koruma elektrotları yerleştirilmekte ve bu şekilde, transformatörlerin aşırı gerilimlere karşı korunabileceği varsayılmaktadır. Bazı teknik yayın ve yönetmeliklerde de bu yönde değerlendirmeler yer almaktadır $[2,11,12]$. 


\section{Deneysel DüZen Ve Prosedür}

Orta gerilim dağıtım transformatörlerinde, aşırı gerilimlere karşı koruma amaçlı olarak da kullanıldıkları göz önüne alınarak, çalışma karakteristiklerini incelemek ve korumada etkinliklerini belirlemek amacıyla belirli açıklıklara sahip koruma elektrotlarında darbe gerilimlerine dayanma deneyleri yapılmıştır. Deneylerde, gerilim kaynağı olarak, 240 kV ve 600 J'lük standart yıldırım darbe gerilimi $(1,2 / 50 \mu \mathrm{s})$ üreteci kullanılmıştır. Uygulanan darbe gerilimlerinin genlikleri, çevirme oranı $\mathrm{n}=1,076 \mathrm{kV} / \mathrm{V}$ olan, kalibrasyonlu kapasitif bir gerilim bölücü kullanılarak, uygun bir hafızalı-dijital osiloskop yardımıyla ölçülmüş ve osilogramları kaydedilmiştir.

Deneyler, dağıtım sistemlerinde yaygın olarak kullanılan gerilim düzeyi olması nedeniyle 36 kV'luk, koruma elektrotlarına sahip transformatör tipi bir geçit izolatörü üzerinde yapılmıştır (Şekil 3). Koruma elektrotları, işletmede kullanılan tipte, $\Phi 8 \mathrm{~mm}$ çapında, uçları kısmen yuvarlatılmış, paslanmaz elektrotlardır. Deneylerde, alt elektrot topraklanmış, üst elektrot darbe gerilimi üretecine bağlanmıştır.

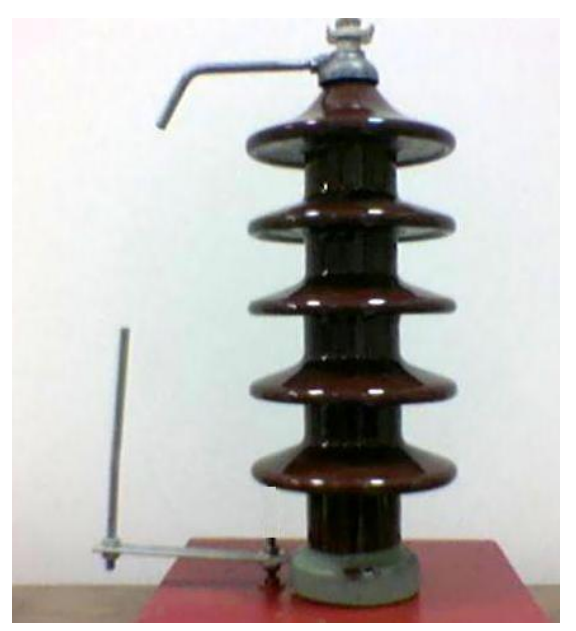

Şekil 3. Deneylerde kullanılan koruma elektrotları ve 36 kV'luk transformatör tipi geçit izolatörü

Deneylerde ortam koşulları, sıcaklık, basınç ve bağıl nem oranı sırasıyla

$\mathrm{t}=25-27^{\circ} \mathrm{C}$,

$\mathrm{p}=962-968 \mathrm{hPa}$

$\mathrm{h}=\% 78-85$

olarak kaydedilmiştir. Ortam sıcaklığı ve basıncına göre, Eşt. 9'da verilen ifade kullanılarak bağıl hava yoğunluğu düzeltme katsayıları hesaplanmış ve elde edilen değerler deney sonuçlarına yansıtılmıştır. Düzeltme katsayıs1, $\mathrm{t}_{0}=20^{\circ} \mathrm{C}$ ve $\mathrm{p}_{0}=1013 \mathrm{hPa}$ olmak üzere genel olarak,

$\delta=\frac{p}{p_{0}} \cdot \frac{273+t_{0}}{273+t}$

biçiminde tanımlanmaktadır. Öte yandan, deney gerilimleri ve açıklıklar göz önüne alınarak, ortam bağıl neminin deney sonuçlarına etkisi göz ardı edilmiştir [21].

Deneylerde atlama gerilimi olarak, ilgili standartlarda tanımlandığ gibi, \%90 olasılıkla atlama oluşturan gerilim değeri alınmıştır [21]. Bu amaçla deney cismine, aynı tepe değere sahip, 10'ar darbe uygulanmış ve belirli gerilimlerde atlama oluşturan darbe sayıları belirlenmiştir. Darbe gerilimlerinin 
ardışık olarak uygulanmalarında, oluşan iyonizasyonun dağılması için, 45-60 saniye kadar beklenmiştir. Bu süreç, pozitif ve negatif darbe gerilimlerinde ayrı ayrı olmak üzere, her bir elektrot açıklığı için, en az üç kez tekrarlanıp, gerilimlere karşı düşen atlama oranları kaydedilmiştir. Elde edilen gerilim-atlama oranı verilerine ilişkin değişim grafikleri çizilmiştir. Her bir grafik, en küçük kareler yöntemine dayanan bir algoritma ile doğruya (birinci dereceden eğriye) dönüştürülmüştür. Söz konusu doğru denklemi kullanılarak, \%90 olasılıkla atlama oluşturan gerilim değeri elde edilmiş ve bu değer atlama gerilimi olarak alınmıştır $[22,23]$.

\section{DENEYSEl SONuCLLaR}

Koruma elektrotlarına, orta gerilimler düzeyinde kullanılması önerilen elektrot açıklıkları dikkate alınarak, her bir açıklık için sırasıyla pozitif ve negatif darbe gerilimleri uygulanarak, atlama gerilimleri ve atlama süreleri belirlenmiştir.

\section{A. POZITIF DARBE GERILIMI}

Deneylerde kullanılan darbe gerilimi üreteci ile elde edilmiş pozitif bir standart yıldırım darbe geriliminin osilogramı, Şekil 4'te verilmiştir $\left(\mathrm{U}_{\mathrm{t}}=1,076 \mathrm{kV} / \mathrm{V} \times 173 \mathrm{~V}=186,1 \mathrm{kV}\right)$.

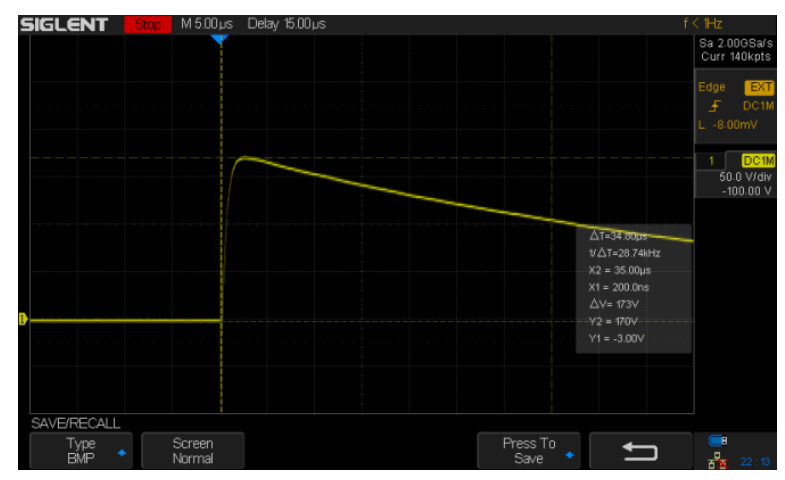

Şekil 4. Koruma elektrotlarına uygulanan bir pozitif standart yıldırım darbe gerilimi osilogramı

$$
\left(U_{t}=186,1 \mathrm{kV}\right)
$$

Elektrotlarda atlama oluşturan pozitif bir darbe geriliminin osilogramı, Şekil 5'te gösterilmiştir. Örnek olarak verilen bu osilogramda, atlama oluşturan darbe geriliminin normal koşullara indirgenmiş tepe değerinin, $U_{a}=201,3 \mathrm{kV}\left(U_{a t}=U \times n / \delta\right)$ ve bu gerilimde atlama süresinin, $t_{a} \cong 4,4 \mu$ s olduğu görülmektedir.

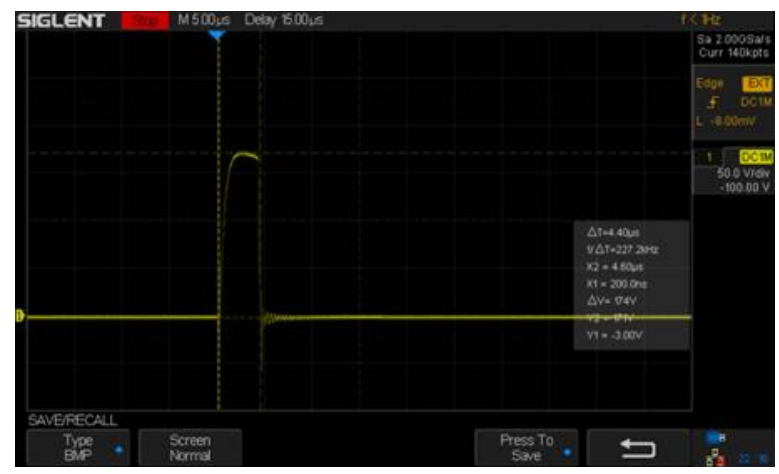


Şekil 5. Koruma elektrotlarında $(a=220 \mathrm{~mm})$ atlama oluşturan pozitif bir darbe geriliminin osilogramı

$$
\left(U_{a}=201,3 \mathrm{kV}, t_{a} \simeq 4,4 \mu \mathrm{s}\right)
$$

Koruma elektrotlarında orta gerilim düzeyleri için önerilen açıklıklarda elde edilen pozitif darbe atlama gerilimlerinin tepe değerleri, $\% 50$ atlama $\left(U_{50}\right)$ gerilimleri ve deneylerde ölçülen atlama

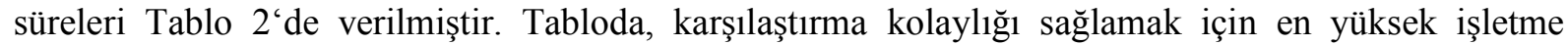
gerilimleri ve koruma elemanları kullanılması durumunda, aşırı gerilimler için tanımlanan (izin verilen) en yüksek gerilim $\left(\mathrm{U}_{\mathrm{k}}\right)$ değerleri de verilmiştir.

Tablo 2. Koruma elektrotlarında açıklı̆̆a bağlı olarak en yüksek işletme gerilimleri, pozitif darbe atlama gerilimleri, \%50 atlama gerilimleri ve ölçülen atlama süreleri

\begin{tabular}{cccccc}
\hline $\begin{array}{c}\mathbf{a} \\
(m m)\end{array}$ & $\begin{array}{c}\mathbf{U}_{\mathbf{i}} \\
(k V)\end{array}$ & $\begin{array}{c}\mathbf{U}_{\mathbf{k}} \\
(k V)\end{array}$ & $\begin{array}{c}\mathbf{U}_{\mathbf{a}} \\
(k V)\end{array}$ & $\begin{array}{c}\mathbf{U}_{\mathbf{5 0}} \\
(k V)\end{array}$ & $\begin{array}{c}\mathbf{t}_{\mathbf{a}} \\
(\mu s)\end{array}$ \\
\hline 60 & 7,2 & 26 & 74,3 & 65,9 & $2-20$ \\
\hline 85 & 12 & 40 & 86,4 & 84,8 & $4-18$ \\
\hline 115 & 17,5 & 60 & 107,8 & 103,9 & $10-18$ \\
\hline 155 & 24 & 80 & 139,6 & 133,9 & $8-20$ \\
\hline 180 & 27,5 & 100 & 155,9 & 147,3 & $5-18$ \\
\hline 220 & 36 & 120 & 190,9 & 175,7 & $4-18$ \\
\hline
\end{tabular}

\section{B. NEGATIF DARBE GERİLIMI}

Darbe gerilimi üreteci ile elde edilen negatif bir standart yıldırım darbe geriliminin osilogramı, Şekil 6'da verilmiştir $\left(\mathrm{U}_{\mathrm{t}}=1,076 \mathrm{kV} / \mathrm{V} \times 163 \mathrm{~V}=175,4 \mathrm{kV}\right)$.

Koruma elektrotlarında atlama oluşturan negatif bir darbe geriliminin osilogramı, Şekil 7'de verilmiştir. Osilogramda, atlama oluşturan negatif darbe geriliminin, normal koşullara indirgenmiş tepe değerinin, $U_{a}=199 \mathrm{kV}\left(\mathrm{U}_{\mathrm{t}}=\mathrm{U} \times \mathrm{n} / \delta\right)$ ve bu gerilimde atlama süresinin, $\mathrm{t}_{\mathrm{a}} \cong 4 \mu$ s olduğu görülmektedir.

Farklı elektrot açıklıklarında elde edilen negatif darbe atlama gerilimlerinin tepe değerleri, $\% 50$ atlama $\left(\mathrm{U}_{50}\right)$ gerilimleri ve deneylerde ölçülen atlama süreleri Tablo 3 'te verilmiştir. Açıklıklara karşı düşen en yüksek işletme gerilimleri ve koruma elemanları kullanılması durumunda, aşırı gerilimlerin izin verilen en yüksek değerleri, karşılaştırma kolaylığı sağlaması için tekrar verilmiştir.

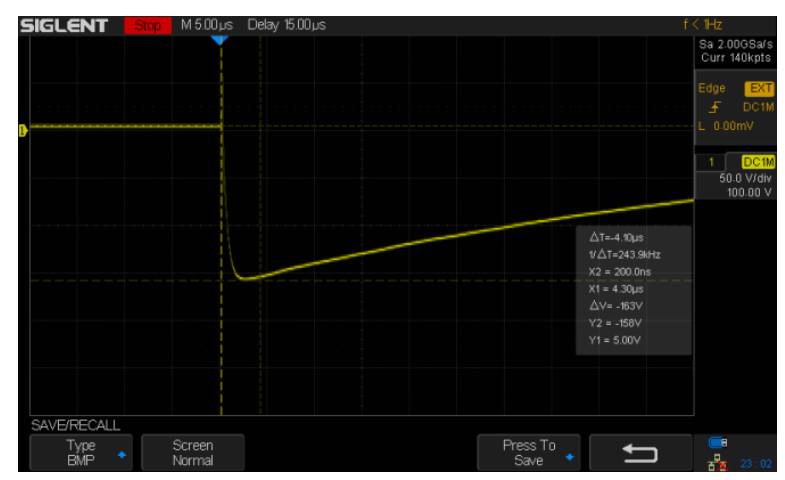

Şekil 6. Negatif standart ylldırım darbe gerilimi osilogramı $\left(U_{t}=175,4 \mathrm{kV}\right)$ 


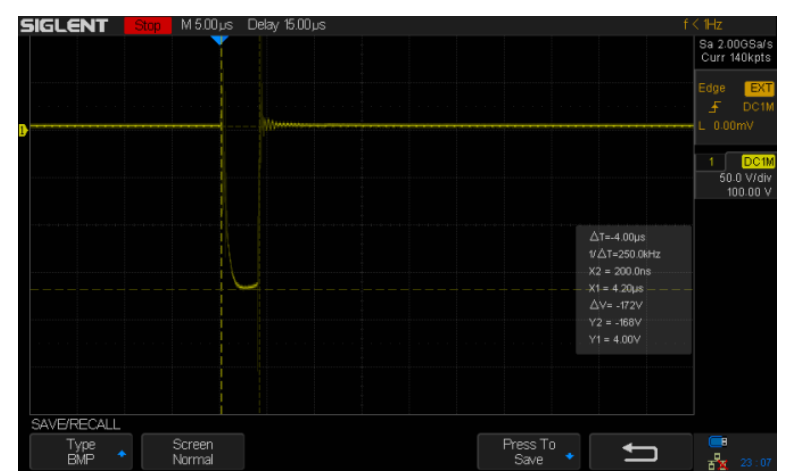

Şekil 7. Elektrotlarda $(a=220 \mathrm{~mm})$ atlama oluşturan negatif bir darbe geriliminin osilogramı

$$
\left(U_{a}=199 \mathrm{kV}, t_{a} \simeq 4 \mu \mathrm{s}\right)
$$

Tablo 3. Elektrotlarda açıklı̆̆a bă̆lı olarak en yüksek işletme gerilimleri, negatif darbe atlama gerilimleri, \%50 atlama gerilimleri ve ölçülen atlama süreleri

\begin{tabular}{cccccc}
\hline $\mathbf{a}$ & $\mathbf{U}_{\mathbf{i}}$ & $\mathbf{U}_{\mathbf{k}}$ & $\mathbf{U}_{\mathbf{a}}$ & $\mathbf{U}_{\mathbf{5 0}}$ & $\mathbf{t}_{\mathbf{a}}$ \\
$(\mathrm{mm})$ & $(k V)$ & $(k V)$ & $(k V)$ & $(k V)$ & $(\mu s)$ \\
\hline 60 & 7,2 & 26 & 68,9 & 63,3 & $3-16$ \\
\hline 85 & 12 & 40 & 87,4 & 84,8 & $3-10$ \\
\hline 115 & 17,5 & 60 & 109,7 & 105,8 & $4-20$ \\
\hline 155 & 24 & 80 & 138 & 134,8 & $5-20$ \\
\hline 180 & 27,5 & 100 & 168,6 & 165,7 & $5-20$ \\
\hline 220 & 36 & 120 & 206,3 & 204,2 & $3-24$ \\
\hline
\end{tabular}

\section{DENEY SONUCLARININ İRDELENMESI}

Dağıtım sistemlerinde kullanılan aygıtların darbe geriliminde dayanma düzeyleri ve bu aygıtlarda, aşırı gerilimlere karşı koruma aygıtlarının (parafudrların) kullanılması durumunda izin verilen darbe gerilimi değerleri ilgili standartlarda tanımlanmıştır. Koruma elektrotlarının deneysel olarak incelenen elektrot açıklıklarında elde edilen atlama gerilimlerinin, genel olarak izin verilen değerlerin üzerinde olduğu görülmektedir.

Koruma elektrotlarında, işletme gerilimleri ile bu gerilimler için seçilen açıklıklarda her iki kutbiyette elde edilen darbe atlama gerilimlerinin değişimleri, Şekil 8'de verilmiştir. Koruma aygıtlarının kullanılması durumunda, izin verilen darbe gerilimi düzeyleri de Şekil 8'de gösterilmiştir. 


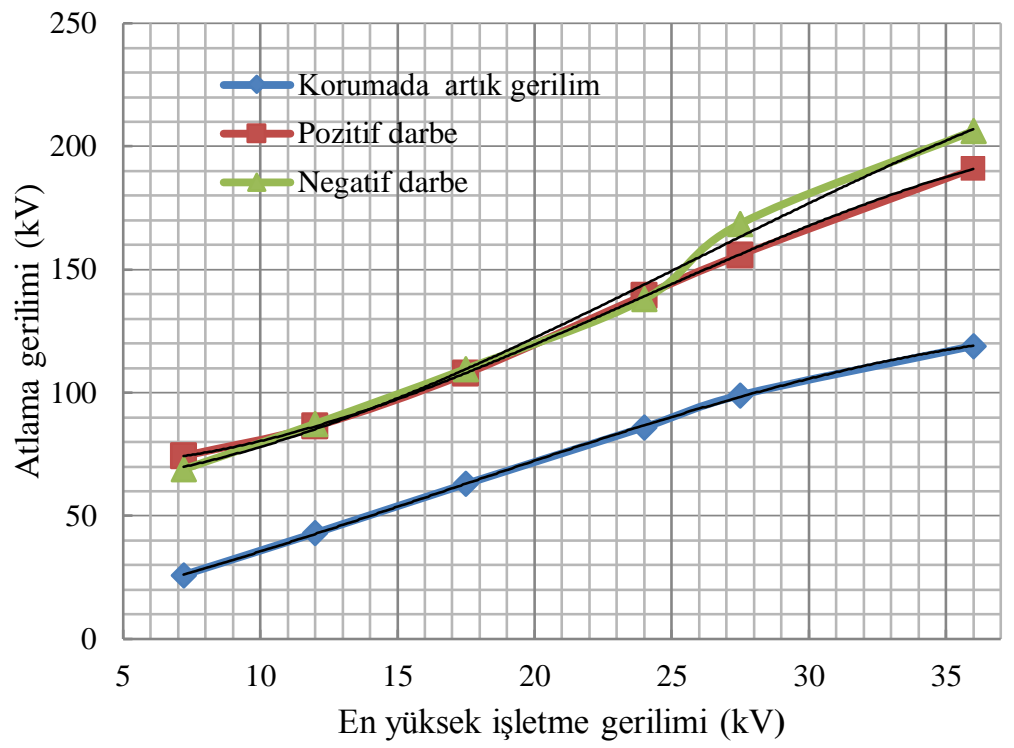

Şekil 8. Elektrotlarda darbe atlama gerilimlerinin en yüksek işletme gerilimi ile değişimi

Deneysel sonuçlar, koruma elektrotlarında atlama gerilimlerinin, izin verilen gerilim düzeylerinden çok daha yüksek olduğunu göstermektedir. Söz konusu artışlar, büyük elektrot açıklıklarında \%60 düzeyinde iken; küçük açıklıklarda \%250 düzeylerine ulaşmaktadır. Büyük açıklıklarda $(180 \mathrm{~mm}$ ve $220 \mathrm{~mm}$ ) negatif darbede atlama gerilimlerinin, pozitif darbedekilere göre \%8 kadar daha yüksek oldukları görülmektedir. Bu sonuç, elektrot açıklığı büyüdükçe elektrik alan dağılımının giderek daha az düzgün olduğunu teyit etmektedir. Bilindiği gibi, düzgün olmayan alan dağılımına sahip, hava yalıtımlı bir sistemin negatif darbe gerilimine dayanma düzeyi, pozitif darbe gerilimindekine göre daha yüksek olmaktadır.

Deneysel olarak belirlenen atlama gerilimlerinin, izin verilen aşırı gerilimlerin üzerinde olmasının yanısıra; aygıtların darbe gerilimi dayanma düzeylerinin de oldukça üzerinde oldukları görülmektedir. Örneğin, 36 kV'luk şebekede kullanılan aygıtların, genel olarak $170 \mathrm{kV}$ 'luk darbe dayanma düzeyinde olması gerekmektedir [24]. Deney sonuçları, $36 \mathrm{kV}$ 'luk işletme gerilimi için önerilen $220 \mathrm{~mm}$ açıklığa sahip koruma elektrotlarında elde edilen atlama gerilimlerinin, 190-205 kV mertebesinde olduğunu göstermektedir. Buna göre, koruma elektrotlarının çalışma gerilimleri, korunması amaçlanan aygıtların darbe dayanma düzeylerinin de üzerinde olabilmektedir.

Elektrotlarda ölçülen atlama sürelerinin, pozitif darbe geriliminde 2-20 $\mu$ s, negatif darbe geriliminde ise 2-25 $\mu$ s kadar olduğu görülmektedir. Atlama süresi, koruma elektrotlarının çalışmaya başlama süresi olarak tanımlanabilir. Bu bakımdan, yürüyen dalgaların ışık hızı mertebesinde hızlarla yayıldığı da göz önüne alındığında, elektrotlar etkin duruma geçene kadar, korunması amaçlanan aygıtların tehlikeli zorlanmalara maruz kalabilecekleri anlaşılmaktadır.

Deneysel sonuçlar, gerek atlama gerilimi düzeyleri, gerekse çalışma süreleri açısından; koruma elektrotlarının, dağıtım transformatörü gibi aygıtları aşırı gerilimlere karşı korumada yetersiz kaldıklarını göstermektedir. Elektrotların çalışma gerilimleri, aygıtların darbe dayanma düzeylerinin de üzerinde olabildiğinden, incelenen açıllıklarda; diğer bir deyişle orta gerilim şebekelerinde bunların, izolatör koruma aygıtı olarak değerlendirilmesinin de doğru olmayacağı sonucuna varılmıştır.

İşletme gerilimlerine göre, kullanılagelen elektrot açıklıklarının düşürülmesi de doğru bir yaklaşımın olmayacaktır. Çünkü, bu durumda gerilim yükselmeleri gibi olaylarda, elektrotların gereksiz çalışması gibi sorunlarla karşılaşma olasıllığı ortaya çıkabilecektir. Konu ile ilgili olarak koruma elektrotlarında, her bir açıklık için farklı darbe gerilimlerinde atlama sürelerinin belirlenmesi ve bu veriler 
kullanılarak, darbe karakteristiklerinin çıkarılmasına yönelik bir çalışma da yapılabilir. Böylece, elde edilen karakteristik ile korunması söz konusu olan aygıtın darbe karakteristiği karşılaştırılarak da değerlendirme yapılabilir.

\section{SONUC}

Koruma elektrotları, özellikle iletim sistemi izolatörlerinde, aşırı gerilim kaynaklı bir atlama sonucunda oluşabilecek bir ark1, yüzeyden uzaklaştırarak, izolatörlerin hasar görmesini önlemek amacıyla kullanılırlar. Bunun yanında, dağıtım transformatörleri geçit (bushing) izolatörlerinde de yaygın olarak kullanılmakta; böylece transformatörleri, aşırı gerilimlere karşı koruyabildikleri düşünülmektedir.

Ancak, deneysel sonuçlar, koruma elektrotlarının, gerek çalışmaya başlama gerilimleri, gerekse çalışma süreleri dikkate alındığında, dağıtım transformatörlerinde öngörülen korumayı yapamadıklarını göstermektedir. Ayrıca, elektrotlar arasında oluşan arkın sönmesi, işletme geriliminin, dolayısıyla şebeke enerjisinin kesilmesini gerektirmektedir.

Sonuç olarak, koruma elektrotlarının aşırı gerilimlere karşı koruma aygıtı olarak değerlendirilemeyeceği görülmektedir. Belirlenen atlama gerilimleri, aygıtların dayanma düzeylerinin üzerinde olabildiğinden, orta gerilim şebekelerinde geçit izolatörleri üzerine koruma elektrotları yerleştirmenin anlamsız olduğu kanaatine varılmıştır.

\section{KAYNAKLAR}

[1] M. Özkaya, Yüksek Gerilim Tekniği, Cilt 2, 2. bask1, İstanbul, Türkiye, Birsen Yayınevi, 1996, böl. 7, ss. 167-178.

[2] Elektrik kuvvetli akım tesisleri yönetmeliği, T.C. Resmi Gazete, Sayı: 24246, 10 Kasım 2000.

[3] H.M. Ryan, High Voltage Engineering and Testing, $2^{\text {nd }}$ Ed., London, United Kingdom, The Institution of Electrical Engineers, 2001, chap.2, pp. 62-84.

[4] Parafudrlar-bölüm 1: A.A. Sistemleri için-değişken dirençli tip atlama aralıkl parafudrlar, Türk Standartlar Enstitüsü TS EN 60099-1, 1997 (İptal edilmiş standart: 23.10.2015).

[5] H. İsmailoğlu, "Aşırı gerilimler, oluşumları, etkileri ve aşırı gerilimlere karşı koruma," Elektrik Tesisat Mühendisliği Ulusal Kongresi - Yüksek Gerilim Çalıştayı, İzmir, Türkiye, 2009, s.8088.

[6] IEEE recommended practice for electric power distribution for industrial plants, IEEE Std $141,1993$.

[7] A.R. Hileman, Insulation Coordination for Power Systems, New York, United States of America, Marcel Dekker Inc., 1999, chap.9, pp. 313-355.

[8] Parafudrlar-bölüm 4: A.A. Sistemleri için ark aralı̆̆ bulunmayan metal oksit parafudrlar, Türk Standartlar Enstitüsü TS EN 60099-4, 2006.

[9] Surge arresters-part 4: Metal-oxide surge arresters without gaps for a.c. systems, International Elecrotechnical Commission IEC 60099-4, 2014. 
[10] IEEE guide for the application of metal-oxide surge arrester for alternating-current systems, IEEE Std C62.22, 2009.

[11] E. Saçkesen, A. Amaç, Koruma sistemleri, Muğla, TEİAŞ-Soma Elektrik Tek. Gel. ve Eğitim Merkezi Müdürlüğü Yayınları, 2001.

[12] TMMOB-Elektik Mühendisleri Odası, Elektrik yüksek gerilim tesislerinde işletme sorumluluğu eğitimi seminer notları, Ankara, 2005.

[13] IEEE guide for improving the lightning performance of electric power overhead distribution lines, IEEE Std 1410, 2004.

[14] Leitsätze für die bemessung und prüfung der isolierung elektrischer anlagen für wechselspannungen von $1 \mathrm{kV}$ und darüber, VDE 0111-2.61, 1961.

[15] Bestimmungen für die bemessung und prüfung der 1solierung elektrischer anlagen und betriebsmittel für wechselspannungen über $1 \mathrm{kV}$, VDE 0111-12.66, 1966.

[16] B.R. Gungor, Power Systems, Florida, United States of America, Harcourt Brace Jovanovich Inc., 1988, chap.3, pp. 106-136.

[17] H. Saadat, Power System Analysis, Singapore, McGraw-Hill Co., 1999, chap.4, pp. 102-132.

[18] E. Kuffel, W.S. Zaengl and J. Kuffel, High Voltage Engineering - Fundamentals, ${ }^{\text {nd }}$ Ed., Oxford, United Kingdom, Butterworth-Heinemann, 2000, chap. 8, pp. 492-506.

[19] F.A.M. Rizk and G.N. Trinh, High Voltage Engineering, Florida, United States of America, CRC Press Taylor Francis Group, 2014, chap.1, pp. 1-23.

[20] Cigre Report 365, "On the use of power arc protection devices for composite inulators on transmission lines, WG B2.21, 2008.

[21] High-voltage test techniques-part 1: General definitions and requirements, International Electrotechnical Commission IEC 60060-1, 2010.

[22] H. İsmailoğlu "Darbe geriliminde sıkıştırılmış gazlarda delinme," Doktora tezi, Elektrik Mühendisliği Bölümü, İstanbul Teknik Üniversitesi, İstanbul, Türkiye, 1996.

[23] H. Ismailoglu, O. Kalenderli, M. Ozkaya and I. Gonenc, "Determination of impulse breakdown voltage using least squares method," IEEE 1997 Annual Report Conference on Electrical Insulation and Dielectric Phenomena, Minneapolis, United States of America, 1997, vol. I, pp. 246249.

[24] Ölçü transformatörleri-bölüm 1: Genel kurallar, Türk Standartlar Enstitüsü TS EN 61869-1, 2010 . 